\title{
Assessment of the Mutagenic Activity of Extracts of Brazilian Propolis in Topical Pharmaceutical Formulations on Mammalian Cells In Vitro and In Vivo
}

\author{
Juliana Marques Senedese, ${ }^{1}$ Aline Rafaela Rodrigues, ${ }^{1}$ Michelle Andrade Furtado, ${ }^{1}$ \\ Viviane Dias Faustino, ${ }^{1}$ Andresa A. Berretta, ${ }^{2,3}$ \\ Juliana M. Marchetti, ${ }^{2}$ and Denise Crispim Tavares ${ }^{1}$ \\ ${ }^{1}$ Universidade de Franca, Av. Dr Armando Salles de Oliveira, 201, 14404-600 Franca, São Paulo, Brazil \\ ${ }^{2}$ Faculdade de Ciências Farmacêuticas de Ribeirão Preto, Universidade de São Paulo, Ribeirão Preto, São Paulo, Brazil \\ ${ }^{3}$ Apis Flora Industrial e Comercial Ltda, Ribeirão Preto, São Paulo, Brazil \\ Correspondence should be addressed to Denise Crispim Tavares, denisecrispim2001@yahoo.com
}

Received 4 April 2008; Accepted 30 May 2008

Copyright (C) 2011 Juliana Marques Senedese et al. This is an open access article distributed under the Creative Commons Attribution License, which permits unrestricted use, distribution, and reproduction in any medium, provided the original work is properly cited.

\begin{abstract}
Propolis possesses various biological activities such as antibacterial, antifungal, anti-inflammatory, anesthetic and antioxidant properties. A topically applied product based on Brazilian green propolis was developed for the treatment of burns. For such substance to be used more safely in future clinical applications, the present study evaluated the mutagenic potential of topical formulations supplemented with green propolis extract (1.2, 2.4 and 3.6\%) based on the analysis of chromosomal aberrations and of micronuclei. In the in vitro studies, 3 -h pulse $\left(\mathrm{G}_{1}\right.$ phase of the cell cycle) and continuous $(20 \mathrm{~h})$ treatments were performed. In the in vivo assessment, the animals were injured on the back and then submitted to acute $(24 \mathrm{~h})$, subacute ( 7 days) and subchronic (30 days) treatments consisting of daily dermal applications of gels containing different concentrations of propolis. Similar frequencies of chromosomal aberrations were observed for cultures submitted to 3-h pulse and continuous treatment with gels containing different propolis concentrations and cultures not submitted to any treatment. However, in the continuous treatment cultures treated with the $3.6 \%$ propolis gel presented significantly lower mitotic indices than the negative control. No statistically significant differences in the frequencies of micronuclei were observed between animals treated with gels containing different concentrations of propolis and the negative control for the three treatment times. Under the present conditions, topical formulations containing different concentrations of green propolis used for the treatment of burns showed no mutagenic effect in either test system, but $3.6 \%$ propolis gel was found to be cytotoxic in the in vitro test.
\end{abstract}

\section{Introduction}

Injuries caused by burns are the third most frequent cause of accidental death in all age groups, with $75 \%$ of these lesions resulting from the victim's action and occurring at home. In the United States, 70000 individuals are hospitalized every year with severe injuries caused by thermal trauma [1]. Burns are caused by physical (temperature, radiation and electricity) and chemical agents (acids and alkalis), and vary in degree according to the intensity or concentration of the causal agents and extent of exposure [2].

The skin is a biological interface between the environment and organism and represents the first line of defense against external noxious stimuli such as ultraviolet light, visible irradiation, pro-oxidant chemicals, infection and ionizing radiation [3]. Topical administration of antioxidants provides an efficient way to improve the endogenous cutaneous protection system [4].

A topically applied product based on propolis was developed using as vehicle a polymeric system consisting of hydrophilic poly(oxyethylene)-poly(oxypropylene)-poly(oxyethylene) polymers (Poloxamer 407), inert and atoxic substances able to generate thermoresistant gel-like colloidal solutions in the presence of water, with the latter affecting the behavior of the solution and the molecular diffusion of the active substance $[5,6]$. The low toxicity and reduced skin 
irritation of Poloxamer 407 encouraged the evaluation of potential dermatological applications of these gels, particularly in the treatment of burns [7], in view of their advantages such as easy application and removal of the preparation, as well as the possibility of maintaining the therapeutic concentration at the site of application. A surgically induced injury was found to be completely healed within a period of 7 days. In addition, gel containing 3.6\% propolis led to evident epithelial reconstruction after 3 days, with the observation of organized connective tissue fibers and numerous fibroblasts [8].

Propolis is produced by bees from plant resins and exudates, and its colour, consistency and chemical composition are intimately related to the flora visited by the bees and to the season during which it is collected [9]. At present, more than 300 compounds, mainly polyphenols, have been identified as constituents of propolis [10]. Most polyphenols are flavonoids, followed by phenolic acids, esters, aldehydes, ketones, and so forth. [11]. Propolis possesses various biological activities such as anti-inflammatory [12], antibacterial [13], antifungal [14], anesthetic [15] and antioxidant properties $[16,17]$. In addition, it has been used in topical applications as a tissue regenerating agent, which is one of its most popular uses in the world today [18]. However, propolis contains some compounds which are toxic and induce hypersensitivity reactions. The main target organ is the skin, with contact dermatitis being a common manifestation [19].

The mechanisms responsible for the improvement of health conditions observed with the use of propolis in folk medicine are still unknown. To guarantee the safe application of propolis in the pharmaceutical industry, it is important to determine whether topical formulations supplemented with green propolis extract used for the treatment of burns induce DNA damage. Therefore, the aim of the present study was to assess the possible mutagenic effect of these formulations by in vitro analysis of chromosomal aberrations in Chinese hamster ovary $(\mathrm{CHO})$ cells and by the in vivo micronucleus test in Wistar rats.

\section{Materials and Methods}

2.1. Preparation of Test Formulations Containing Propolis Extract. The topical formulations containing standard green propolis extract (SPE-AF) used for the treatment of burns were provided by Apis Flora Comercial e Industrial Ltda., Ribeirão Preto, São Paulo State, Brazil (Patent number PI 0405483-0, published in Revista de Propriedade Industrial no 1778 from January 02, 2005). Green propolis extract was prepared from propolis in natura produced in the region of Oliveira (State of Minas Gerais, Brazil), a region rich in native Baccharis dracunculifolia. The gels were prepared on a weight basis using the cold method according to Schmolka (1972). Concentrations of Poloxamer 407 and of SPE-AF are expressed as percent weight $(\mathrm{w} / \mathrm{v})$. An appropriate amount of Poloxamer 407 was slowly added to cold distilled water $\left(5^{\circ} \mathrm{C}\right)$ under constant stirring. The polymer dispersion was kept in the refrigerator until a clear solution had been formed (6$12 \mathrm{~h}$ ). Appropriate amounts of SPE-AF and polyoxyl castor oil were prepared to yield 1.2, 2.4 and $3.6 \%(\mathrm{w} / \mathrm{v})$ of dry propolis extract and then dissolved in the cold solution. Two control samples were prepared, one consisting of the polymer dispersion and the other of the solubilizing agent used to obtain a clean gel.

2.2. Analysis of Propolis Extract by HPLC. The chromatographic analysis of green propolis extract was performed using a High Performance Liquid Chromatograph (HPLC) Shimadzu equipped with controller SCL-10A $v p$, three pumps LC-10AD, detector diode-array model SPD-M10Avp and software controller Shimadzu Class-VP version 5.02. A Shim-Pack CLC-ODS (M), Shimadzu column $(4.6 \mathrm{~mm} \times$ $250 \mathrm{~mm}$, particle diameter of $5 \mu \mathrm{m}$, pore diameter of $100 \AA$ ) was used. The mobile phase consisted of a buffer solution in pump A $(93.9 \%$ water, $0.8 \%$ acetic acid, $0.3 \%$ ammonium acetate, 5\% methanol) and acetonitrile in pump B. The elution was undertaken using a linear gradient of $25-100 \%$

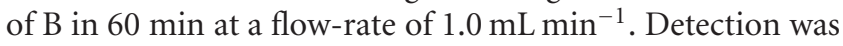
performed at $280 \mathrm{~nm}$.

The phenolic compounds were identified by comparison with the authentic chromatographic standards available at the compounds library of the Pharmacognosy Laboratory of the School of Pharmacy of Ribeirão Preto, São Paulo, Brazil, comparing UV spectra and considering both the maximum lambda and the relative area obtained with the use of two wavelengths $\left(\mathrm{A}_{280 / 320}\right)$.

The crude propolis extract was dissolved in methanol (HPLC grade) to obtain a concentration of $1 \mathrm{mg} \mathrm{mL}^{-1}$. Before analysis, all samples were centrifuged at $1300 \mathrm{rpm}$ and filtered through a $45-\mu \mathrm{m}$ filter.

2.3. Chromosomal Aberrations Assay in $\mathrm{CHO}$ Cells. $\mathrm{CHO}_{9}$ cells were kindly supplied by the Laboratory of Cytogenetics and Mutagenesis, University of São Paulo, Ribeirão Preto, São Paulo, Brazil. Cells were maintained as monolayers in plastic culture flasks $\left(25 \mathrm{~cm}^{2}\right)$ in HAM-F10 (SigmaAldrich, St. Louis, MO, USA) and D-MEM (Sigma-Aldrich) $(1: 1)$ culture media supplemented with $10 \%$ fetal bovine serum (Nutricell), antibiotics $\left(0.01 \mathrm{mg} \mathrm{mL}^{-1}\right.$ streptomycin and $0.005 \mathrm{mg} \mathrm{mL}^{-1}$ penicillin; Sigma-Aldrich), and $2.38 \mathrm{mg} \mathrm{mL}^{-1}$ HEPES (Sigma-Aldrich), at $37^{\circ} \mathrm{C}$ in a BOD type chamber.

Exponentially growing $\mathrm{CHO}$ cells were seeded $\left(1 \times 10^{6}\right.$ cells per flask) and allowed to grow for $20 \mathrm{~h}$ (approximately 1.5 times the normal cell cycle) [20]. The cultures were treated with $5 \mathrm{mg} \mathrm{mL}^{-1}$ of each gel containing different concentrations of propolis $(1.2,2.4$ and $3.6 \%)$, with this being the concentration limit specified by guidelines for cases in which the molecular weight is unknown or mixtures are being tested. Two treatment protocols were used: 3$\mathrm{h}$ pulse treatment and continuous $(20 \mathrm{~h})$ treatment. After the 3-h pulse treatment, the cells were washed twice in phosphate-buffered saline, fresh medium was added and the cultures were incubated at $37^{\circ} \mathrm{C}$ for an additional $17 \mathrm{~h}$. In continuous treatment, $\mathrm{CHO}$ cells were seeded and treated until harvest. The cells were fixed $20 \mathrm{~h}$ after the beginning of treatment in both protocols. Doxorubicin (DXR, Pharmacia 
Brasil Ltda., São Paulo, Brazil) was added to the cultures at concentrations of 1.0 and $2.0 \mu \mathrm{g} \mathrm{mL}^{-1}$ for the continuous and 3-h pulse treatment, respectively, as positive control. Three independent replicates were carried out for each treatment.

Colcemid (Demecolcine, $0.1 \mu \mathrm{g} \mathrm{mL}^{-1}$; Sigma-Aldrich) was added to the culture medium $2 \mathrm{~h}$ before fixation. At harvest, the cells were trypsinized $(0.025 \%)$ and then hypotonized in $1 \%$ sodium citrate solution at $37^{\circ} \mathrm{C}$ for $30 \mathrm{~min}$. The cells were fixed in methanol/acetic acid $(3: 1)$ and the slides were stained with $5 \%$ Giemsa for 5 min.

For the determination of chromosomal aberrations, 100 metaphases were analyzed per culture, for a total of 300 cells per treatment and control, and the aberrations were classified according to Savage [21]. The mitotic index (MI) corresponds to the number of metaphase cells among 2000 cells analysed per culture and is reported as percentage. The MI is expressed as the mean of three replicates. The data obtained were analysed statistically by ANOVA for repeated measures, followed by the Tukey test, with the level of significance set at $\alpha=0.05$. Gaps were recorded but not included in the statistical analysis since their cytogenetic significance has not been well established.

2.4. Micronucleus Assay in Wistar Rats. For the experiments, 30 male Wistar rats (Rattus norvegicus, Berkenout, 1769) with an initial body weight of $45 \mathrm{~g}$, obtained from the Central Animal House, Faculty of Medicine of Ribeirão Preto, University of São Paulo, Brazil, were allocated to three treatment times: acute $(24 \mathrm{~h})$, subacute $(7$ days $)$ and subchronic (30 days). The study protocol was approved by the Ethics Committee for Animal Care of the University of Franca (process 121/05).

Since the topical formulation used in the present study is aimed at the treatment of burn injuries, a lesion was created with a punch on the back of animals previously anesthetized by intraperitoneal administration of ketamine, midazolam and acepram [22].

The concentrations of the propolis extract added to the topical formulations used in the present study, as well as the treatment protocol, were established based on previous histological studies regarding the healing effect of the gel [8]. The animals were treated with gels containing the following concentrations of propolis: 1.2, 2.4 and $3.6 \% \mathrm{w} / \mathrm{v}$. In addition, a group of animals treated with propolis-free gel, a negative control group and a positive control group (50 mg cyclophosphamide $\mathrm{kg}^{-1}$ body weight) were included. Each treatment group consisted of five animals. These groups were submitted to acute, subacute and subchronic treatments with gels containing propolis or not, with the animals being treated and weighed daily.

The frequency of micronuclei was determined in peripheral blood of Wistar rats according to the technique of MacGregor et al. [23]. Peripheral blood smears were obtained $24 \mathrm{~h}$ and 7 and 30 days after the beginning of application of the gels to the dorsal lesions of the animals. The frequency of micronucleated polychromatic erythrocytes (MNPCEs) was determined based on the analysis of 2000 anucleated polychromatic erythrocytes (PCE) per animal. A total of 400 erythrocytes per animal were scored to determine the nuclear division index (NDI, PCE/PCE + NCE [normochromatic erythrocytes]).

Differences in the frequencies of MNPCEs and NDI between groups treated with the different propolis gels at the three exposure times were analysed statistically by the Tukey test, with the level of significance set at $\alpha=0.05$.

\section{Results}

3.1. Analysis of Propolis Extract by HPLC. HPLC analysis of green propolis extract permitted the identification of the following compounds: (i) $p$-coumaric acid; (ii) aromadendrin$4^{\prime}$-methyl ether; (iii) 3-prenyl-p-coumaric acid (drupanin); (iv) 3,5-diprenyl-p-coumaric acid (artepillin C) and (v) baccharin (Figure 1).

\subsection{Chromosomal Aberrations Assay in CHO Cells. The} results obtained for the 3 -h pulse and continuous treatments using gels with different concentrations of propolis and their respective controls are shown in Table 1. Cultures submitted to 3 -h pulse treatment with gels containing 1.2 and $2.4 \%$ propolis showed a small increase in the number of chromosomal aberrations and altered metaphases compared to the control group, but these differences were not statistically significant. In the continuous treatment, gels containing 2.4 and $3.6 \%$ propolis presented slightly higher frequencies of chromosomal aberrations and altered metaphases than the negative control but the difference was not significant $(P>.05)$.

No significant differences in the MI were observed between cultures submitted to 3 -h pulse treatment with gels containing different propolis concentrations and their respective controls. In the continuous treatment, lower MI were observed for cultures treated with gels containing 2.4 and $3.6 \%$ propolis when compared to control, but this decrease was only significant $(P>.05)$ for the $3.6 \%$ propolis gel (Table 1).

3.3. Micronucleus Assay in Wistar Rats. Table 2 shows the mean initial body weight, final body weight and body weight gain during the experimental period. No statistically significant differences in these variables were observed between groups $(P>.05)$.

The frequencies of MNPCEs in peripheral blood of animals submitted to acute, subacute and subchronic treatments with gels containing different propolis concentrations are shown in Table 3. Animals submitted to acute treatment with $1.2 \%$ propolis gel showed a lower frequency of MNPCEs compared to the other groups, but this difference was not statistically significant. In the subacute treatment, no difference in the frequency of MNPCEs was observed between the groups receiving propolis gels and the negative control. In the subchronic treatment, comparison of the frequency between the negative control and the other groups showed a lower frequency of MNPCEs in the group receiving propolisfree gel and the group treated with $3.6 \%$ propolis gel. However, these differences were not significant $(P>.05)$. Thus, acute, subacute or subchronic treatment did not result 


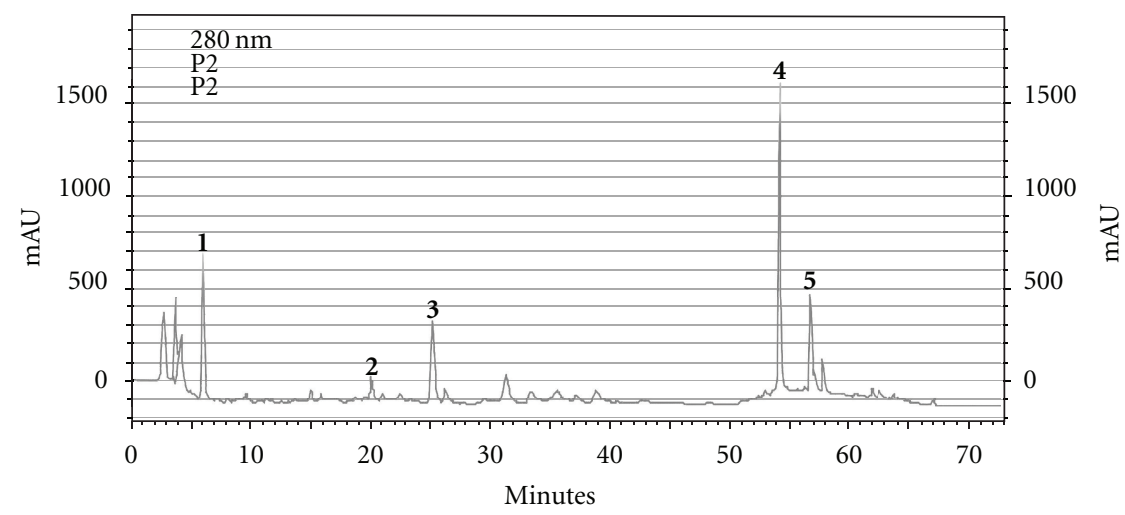

FIGURE 1: HPLC chromatographic profile of green propolis extract. (1) p-coumaric acid; (2) aromadendrin-4' ${ }^{\prime}$-methyl ether; (3) 3-prenyl- $p$ coumaric acid (drupanin); (4) 3,5-diprenyl-p-coumaric acid (artepillin C) and (5) baccharin.

TABLE 1: Number of abnormal cells and mitotic index (MI) obtained for CHO cells submitted to 3-h pulse or continuous (20 h) treatment with gels containing different concentrations of propolis and their respective controls.

\begin{tabular}{lcccccc}
\hline \multirow{2}{*}{ Treatments } & \multicolumn{2}{c}{$\mathrm{MI}(\%) \pm \mathrm{SD}^{\mathrm{c}}$} & \multicolumn{2}{c}{ Abnormal cells $\pm \mathrm{SD}^{\mathrm{c}}$} & \multicolumn{2}{c}{ Aberration frequency } \\
& 3-h pulse & $20 \mathrm{~h}$ & 3-h pulse & 20 h & 3-h pulse & 20 h \\
\hline Control & $6.05 \pm 2.00$ & $6.08 \pm 1.32$ & $2.00 \pm 2.00$ & $3.00 \pm 2.00$ & 0.02 & 0.03 \\
DMSO $^{\mathrm{a}}$ & $4.92 \pm 0.40$ & $4.72 \pm 2.83$ & $2.00 \pm 1.00$ & $3.70 \pm 2.34$ & 0.02 & 0.04 \\
Without propolis & $4.26 \pm 0.60$ & $5.15 \pm 0.02$ & $2.40 \pm 1.53$ & $2.70 \pm 0.58$ & 0.03 & 0.03 \\
$1.2 \%$ Propolis & $9.08 \pm 0.60$ & $6.77 \pm 1.44$ & $4.40 \pm 2.52$ & $3.70 \pm 4.72$ & 0.04 & 0.04 \\
2.4\% Propolis & $8.48 \pm 1.27$ & $2.63 \pm 1.61$ & $3.70 \pm 2.52$ & $5.70 \pm 1.15$ & 0.04 & 0.06 \\
$3.6 \%$ Propolis & $8.13 \pm 1.81$ & $0.90 \pm 0.52^{*}$ & $1.70 \pm 0.58$ & $7.00 \pm 5.00$ & 0.02 & 0.07 \\
DXR $^{\mathrm{b}}$ & $7.67 \pm 1.87$ & $5.97 \pm 2.91$ & $15.40 \pm 4.16$ & $15.00 \pm 2.64$ & 0.15 & 0.16 \\
\hline
\end{tabular}

One-hundred metaphases were analyzed per culture, for a total of 300 cells per treatment.

${ }^{\mathrm{a}} \mathrm{DMSO}$, dimethylsulfoxide, $0.5 \mu \mathrm{L} / \mathrm{mL},{ }^{\mathrm{b}} \mathrm{DXR}$, doxorubicin $\left(1.0\right.$ and $2.0 \mu \mathrm{g} / \mathrm{mL}$ in continuous and $3-\mathrm{h}$ pulse treatment, resp.), ${ }^{\mathrm{c}}$ Values are mean $\pm \mathrm{SD}$.

* Significantly different from the control group $(P<.05)$.

in an increase in the frequency of MNPCEs in animals treated with gels containing different propolis concentrations when compared to the negative control or to animals treated with propolis-free gel.

Comparison of the frequencies of MNPCEs between the different exposure times revealed a nonsignificant reduction in all treatment groups at 7 and 30 days compared to the 24 -h treatment. This decrease is probably related to the adaptation of the animal to the housing conditions.

Analysis of the NDI obtained for the acute, subacute and subchronic treatments showed no significant difference in the ratio of polychromatic erythrocytes to total erythrocytes between animals treated with gels for burns containing different propolis concentrations and controls.

\section{Discussion}

From the biological activities found for propolis, the antioxidant activity deserves special interest since it suggests propolis could be successfully applied topically to prevent and treat skin damages. Recently, propolis extract added to topical formulations has been shown to maintain its antioxidant activity, protecting skin against damage caused by free radicals [16].
The antioxidant activity of green propolis has been investigated by Simões et al. [24], who studied the biological effects of different extracts and fractions of green propolis. A correlation was observed between the antioxidant activity and chemical composition of its different fractions, with special emphasis on the presence of flavonoids and $p$ coumaric acid derivatives. The authors concluded that the components of propolis act through different mechanisms sequestering reactive oxygen species. Artepillin C (3,4-diprenyl-p-coumaric acid), a major constituent of green propolis, is also an excellent scavenger of free radicals similar to catechins [25].

Tavares et al. [26] studied the mutagenic and antimutagenic effects of the green propolis on $\mathrm{CHO}$ cells. The authors showed that, on the one hand, the highest propolis concentration tested resulted in a small but significant increase in the frequency of chromosomal aberrations whereas, on the other hand, the lowest concentration tested significantly reduced the chromosome damage induced by the chemotherapeutic agent DXR. These results indicate that green propolis possesses the characteristics of a "Janus" substance, that is, propolis is mutagenic at higher concentrations, while at lower concentrations it exerts a chemopreventive effect on DXR-induced mutagenicity. Ozkul et al. [27] 
TABLE 2: Mean initial body weight, final body weight and body weight gain of rats and their respective control after 30 days of treatment with gels containing different concentrations of propolis.

\begin{tabular}{lccc}
\hline Treatments $(n=5$ rats/group) & Initial body weight $(\mathrm{g})^{\mathrm{a}}$ & ${\text { Final body weight }(\mathrm{g})^{\mathrm{a}}}^{\mathrm{a}}$ & ${\text { Body weight gain }(\mathrm{g})^{\mathrm{a}}}^{\mathrm{a}}$ \\
\hline Control & $51 \pm 6$ & $322 \pm 7$ & $270 \pm 6$ \\
Without propolis & $47 \pm 9$ & $276 \pm 11$ & $229 \pm 16$ \\
$1.2 \%$ Propolis & $48 \pm 9$ & $257 \pm 25$ & $209 \pm 23$ \\
$2.4 \%$ Propolis & $51 \pm 10$ & $262 \pm 38$ & $211 \pm 32$ \\
$3.6 \%$ Propolis & $50 \pm 7$ & $288 \pm 49$ & $239 \pm 43$ \\
\hline
\end{tabular}

${ }^{\mathrm{a}}$ Values are mean $\pm \mathrm{SD}$.

TABLe 3: Frequency of micronucleated polychromatic erythrocytes (MNPCEs) and nuclear division index (NDI) in peripheral blood of male Wistar rats submitted to acute, subacute and subchronic treatments with gels containing different concentrations of propolis and their respective controls.

\begin{tabular}{|c|c|c|c|c|c|c|}
\hline \multirow{2}{*}{ Treatments ( $n=5$ rats/group) } & \multicolumn{2}{|c|}{ Acute } & \multicolumn{2}{|c|}{ Subacute } & \multicolumn{2}{|c|}{ Subchronic } \\
\hline & MNPCEs $^{\mathrm{a}}$ & $\mathrm{NDI}^{\mathrm{b}}$ & MNPCEs $^{\mathrm{a}}$ & $\mathrm{NDI}^{\mathrm{b}}$ & MNPCEs $^{\mathrm{a}}$ & $\mathrm{NDI}^{\mathrm{b}}$ \\
\hline Control & 0.24 & $0.18 \pm 0.06$ & 0.09 & $0.14 \pm 0.03$ & 0.10 & $0.12 \pm 0.02$ \\
\hline Without propolis & 0.32 & $0.21 \pm 0.08$ & 0.08 & $0.14 \pm 0.04$ & 0.03 & $0.10 \pm 0.03$ \\
\hline $1.2 \%$ Propolis & 0.06 & $0.20 \pm 0.05$ & 0.09 & $0.16 \pm 0.03$ & 0.06 & $0.13 \pm 0.02$ \\
\hline 2.4\% Propolis & 0.28 & $0.16 \pm 0.04$ & 0.15 & $0.17 \pm 0.05$ & 0.05 & $0.12 \pm 0.03$ \\
\hline $3.6 \%$ Propolis & 0.28 & $0.20 \pm 0.03$ & 0.15 & $0.13 \pm 0.02$ & 0.03 & $0.12 \pm 0.02$ \\
\hline $\mathrm{CPA}^{\mathrm{a}}$ & 0.89 & $0.15 \pm 0.03$ & 0.89 & $0.15 \pm 0.03$ & 0.89 & $0.15 \pm 0.03$ \\
\hline
\end{tabular}

A total of 2000 cells were analyzed per animal, for a total of 10000 cells per treatment.

${ }^{\mathrm{a}} \mathrm{CPA}$, cyclophosphamide ( $50 \mathrm{mg} / \mathrm{kg}$ body weight), ${ }^{\mathrm{b}}$ Values are percentage, ${ }^{\mathrm{c}}$ Values are mean $\pm \mathrm{SD}$.

also reported mutagenic effect of propolis when tested at high concentrations in human lymphocytes.

In the present study, the topical formulations supplemented with green propolis extract for the treatment of burns were assessed in vitro for their mutagenic effect on $\mathrm{CHO}$ cells and in vivo for their capacity to induce micronuclei in peripheral blood. The results obtained in the in vitro assay showed that 3-h exposure to these topical formulations did not produce any significant increase in chromosomal aberrations. According to Galloway et al. [20], in the case of a negative result in the 3 -h pulse treatment, continuous treatment should be performed. Thus, we submitted $\mathrm{CHO}$ cells to continuous treatment after obtaining a negative result in the 3-h pulse treatment. Similarly, 20-h treatment with propolis gels did not result in an increase of chromosomal aberrations compared to the control culture.

Regarding the test system used in the present study, it should be emphasized that the chromosomal aberrations assay in mammalian cell cultures is one of the most widely used methods for the assessment of mutagenic and/or carcinogenic agents [28]. The sensitivity of the test system was demonstrated by the observation of a significant increase in chromosomal aberrations produced by the positive control substance (DXR) and by the fact that negative control values were within the range reported for the $\mathrm{CHO}$ in vitro test system.

Analysis of the MI showed that gels containing different concentrations of propolis presented no cytotoxic effect, except for the $3.6 \%$ propolis gel which was cytotoxic in the continuous treatment. A nonsignificant increase in the number of chromosomal aberrations was also observed in this treatment. According to Galloway et al. [20], an increased osmolarity of the culture medium may cause an increase in the number of chromosomal aberrations. Thus, the increased frequency of chromosomal aberrations observed might be related to the cytotoxicity of gel containing $3.6 \%$ propolis. This cytotoxicity might be explained in part by the presence of artepillin C, the most abundant compound identified (Figure 1), which has shown in vitro cytotoxic activity in some cell lines. The observed cytotoxicity seemed to be partly attributable to the induction of apoptosis-like DNA fragmentation [29].

It is known that many compounds can yield negative in vitro results and positive in vivo results because of their indirect action and consequent need for metabolic activation. Furthermore, the possibility that many of these positive results may not be relevant in terms of human exposure [30] should be taken into account. For this reason, in addition to the in vitro test, the topical formulations supplemented with green propolis extract for the treatment of burns were also tested for their capacity to induce micronuclei in vivo in rat peripheral blood. The results obtained with the in vivo test system showed that these gels did not increase the frequency of MNPCEs in peripheral blood of rats submitted to acute, subacute or subchronic treatment. Some considerations regarding the test system used in the present study are important. The micronucleus test is the most widely used in vivo assay for the identification of clastogenic and aneugenic agents, and is conducted using the bone marrow or peripheral blood of rodents [31]. In this study the rat peripheral blood was employed because previous histological studies regarding the healing effect of 
the gels containing different concentrations of green propolis were performed using this species [8].

According to Abramsson-Zetterberg et al. [32], since rats have been used as an animal model in conventional toxicological studies, parallel application of the micronucleus test may be advantageous as an indication of the genotoxic effect in this species. In the case of prolonged exposure of rats, a species commonly used in toxicological tests, various peripheral blood samples for the micronucleus test can be obtained from the same animal. Analysis of micronucleated cells in peripheral blood samples obtained at various times along the experiment provides important supplementary information regarding the time that has elapsed since the induction of micronuclei.

With respect to the route of administration used in the present study, it is important to emphasize that MNPCE analysis is adequate for the assessment of the possible mutagenicity of gels containing different concentrations of green propolis and applied dermally. Itoh et al. [33] used the same test system for the evaluation of the antimicrobial agent quinolone applied dermally to mice. The results showed that the method was a useful tool for the detection of in vivo chromosome breaks and for the investigation of the photochemical carcinogenesis of chemicals. Vijayalaxmi et al. [34] observed that jet fuels did not have the potential to induce genotoxicity based on micronucleus studies in the peripheral blood and bone marrow of mice treated dermally.

The increased frequency of MNPCEs observed in animals treated with the known clastogenic agent cyclophosphamide, used as positive control in the present study, indicates that this test system should reveal an increase in the frequencies of MNPCEs in animals treated with gels containing different concentrations of green propolis if the latter were mutagenic. The absence of mutagenicity in rat peripheral blood erythrocytes suggests that these gels are not mutagenic or they are not absorbed systemically when applied dermally.

In the present study, the in vivo micronucleus assay confirmed that the topical formulations supplemented with green propolis extract have no mutagenic effect as demonstrated in the in vitro test.

In conclusion, under the present conditions topical formulations supplemented with green propolis extract used for the treatment of burns showed no mutagenic effect in either test system, but $3.6 \%$ propolis gel was cytotoxic in the in vitro test. The present results contribute to a better understanding of the action of propolis on the human organism, and consequently permit the safer use of topical formulations supplemented with green propolis extract in future clinical applications.

\section{Acknowledgments}

The authors are grateful to Marta Aparecida Augusto from the Animal House of Universidade de Franca for technical assistance. This research was supported by Apis Flora Industrial e Comercial Ltda. and Fundação de Amparo à Pesquisa do Estado de São Paulo (FAPESP).

\section{References}

[1] L. A. Rossi, E. Ferreira, E. C. Costa, E. C. Bergamasco, and C. Camargo, "Burn prevention: perception of the patients and their relative," Revista Latino-Americana de Enfermagem, vol. 11, no. 1, pp. 36-42, 2003.

[2] M. C. M. Souza, I. Ito, D. O. Azevedo, and N. C. A. Oliveira, "Staphylococcus aureus: Estudo de sua ocorrência hospitalar em pacientes, em funcionários e em fontes de unidade de queimados," Jornal Brasileiro de Medicina, vol. 59, pp. 24-30, 1990.

[3] J. Fuchs and L. Packer, "Oxidative stress," in Oxidants and Antioxidants, H. Sies, Ed., pp. 559-583, Academic Press, London, 1991.

[4] A. Saija, A. Tomaino, D. Trombetta et al., "In vitro and in vivo evaluation of caffeic and ferulic acids as topical photoprotective agents," International Journal of Pharmaceutics, vol. 199, no. 1, pp. 39-47, 2000.

[5] I. R. Schmolka, "Artificial skin. I. Preparation and properties of pluronic F-127 gels for treatment of burns," Journal of Biomedical Materials Research, vol. 6, no. 6, pp. 571-582, 1972.

[6] A. Paavola, J. Yliruusi, Y. Kajimoto, E. Kalso, T. Wahlstrom, and P. Rosenberg, "Controlled release of lidocaine from injectable gels and efficacy in rat sciatic nerve block," Pharmaceutical Research, vol. 12, no. 12, pp. 1997-2002, 1995.

[7] R. M. Nalbandian, R. L. Henry, K. W. Balko, D. V. Adams, and N. R. Neuman, "Pluronic F-127 gel preparation as an artificial skin in the treatment of third-degree burns in pigs," Journal of Biomedical Materials Research, vol. 21, no. 9, pp. 1135-1148, 1987.

[8] A. A. Berretta, L. B. Hirooka, L. Lunardi, and J. M. Marchetti, "Evaluation of the healing process obtained with the application of gels containing standardized propolis extract," Evidence-Based Complementary and Alternative Medicine. In preparation.

[9] V. Bankova, "Recent trends and important developments in propolis research," Evidence-Based Complementary and Alternative Medicine, vol. 2, no. 1, pp. 29-32, 2005.

[10] A. Salatino, É. W. Teixeira, G. Negri, and D. Message, "Origin and chemical variation of Brazilian propolis," Evidence-Based Complementary and Alternative Medicine, vol. 2, no. 1, pp. 3338, 2005.

[11] N. Orsolic, S. Terzic, Z. Mihaljevik, L. Sever, and I. Basic, "Effects of local administration of propolis and its polyphenolic compounds on tumor formation and growth," Biological and Pharmaceutical Bulletin, vol. 28, pp. 1928-1933, 2005.

[12] F. A. Santos, E. M. A. F. Bastos, A. B. R. A. Maia et al., "Brazilian propolis: physicochemical properties, plant origin and antibacterial activity on periodontopathogens," Phytotherapy Research, vol. 17, no. 3, pp. 285-289, 2003.

[13] L. Drago, E. De Vecchi, L. Nicola, and M. R. Gismondo, "In vitro antimicrobial activity of a novel propolis formulation (Actichelated propolis)," Journal of Applied Microbiology, vol. 103, no. 5, pp. 1914-1921, 2007.

[14] M. Hronek, D. Vachtlova, Z. Kudlackova, and P. Jilek, "Antifungal effects in selected natural compounds and probiotics and their possible use in prophylaxis of vulvovaginitis," Ceská Gynekologie, vol. 70, pp. 395-399, 2005.

[15] H. Ibricević, A. Kostić, and I. D. Gaon, "The examination of propolis as a potential local anesthetic," Stomatoloski Vjesnik, vol. 10, no. 3-4, pp. 125-128, 1981.

[16] F. D. Marquele, V. M. Di Mambro, S. R. Georgetti, R. Casagrande, Y. M. L. Valim, and M. J. V. Fonseca, "Assessment of the antioxidant activities of Brazilian extracts of propolis 
alone and in topical pharmaceutical formulations," Journal of Pharmaceutical and Biomedical Analysis, vol. 39, no. 3-4, pp. 455-462, 2005.

[17] D. Pezo, J. Salafranca, and C. Nerín, "Determination of the antioxidant capacity of active food packagings by in situ gas-phase hydroxyl radical generation and high-performance liquid chromatography-fluorescence detection," Journal of Chromatography A, vol. 1178, pp. 126-133, 2008.

[18] S. Castaldo and F. Capasso, "Propolis, an old remedy used in modern medicine," Fitoterapia, vol. 73, no. 1, pp. S1-S6, 2002.

[19] K. Münstedt, M. Hellner, A. Hackethal, D. Winter, and R. Von Georgi, "Contact allergy to propolis in beekeepers," Allergologia et Immunopathologia, vol. 35, no. 3, pp. 95-100, 2007.

[20] S. M. Galloway, M. J. Aardema, M. Ishidate Jr. et al., "Report from working group on in vitro tests for chromosomal aberrations," Mutation Research, vol. 312, no. 3, pp. 241-261, 1994.

[21] J. R. K. Savage, "Classification and relationships of induced chromosomal structural changes," Journal of Medical Genetics, vol. 13, no. 2, pp. 103-122, 1976.

[22] R.-H. Hu, Y.-M. Yu, D. Costa et al., "A rabbit model for metabolic studies after burn injury," Journal of Surgical Research, vol. 75, no. 2, pp. 153-160, 1998.

[23] J. T. MacGregor, C. M. Wehr, and D. H. Gould, "Clastogeninduced micronuclei in peripheral blood erythrocytes: the basic of an improved micronucleus test," Environmental Mutagen, vol. 2, pp. 509-514, 1980.

[24] L. M. C. Simões, L. E. Gregório, A. A. Da Silva Filho et al., "Effect of Brazilian green propolis on the production of reactive oxygen species by stimulated neutrophils," Journal of Ethnopharmacology, vol. 94, no. 1, pp. 59-65, 2004.

[25] I. Nakanishi, Y. Uto, K. Ohkubo et al., "Efficient radical scavenging ability of artepillin C, a major component of Brazilian propolis, and the mechanism," Organic and Biomolecular Chemistry, vol. 1, no. 9, pp. 1452-1454, 2003.

[26] D. C. Tavares, G. R. M. Barcelos, L. F. Silva, C. C. Chacon Tonin, and J. K. Bastos, "Propolis-induced genotoxicity and antigenotoxicity in Chinese hamster ovary cells," Toxicology in Vitro, vol. 20, no. 7, pp. 1154-1158, 2006.

[27] Y. Ozkul, H. E. Eroglu, and E. Ok, "Genotoxic potential of Turkish propolis in peripheral blood lymphocytes," Pharmazie, vol. 61, no. 7, pp. 638-640, 2006.

[28] B. Miller, S. Albertini, F. Loucher, V. Thybaud, and E. Lorge, "Comparative evaluation of the in vitro micronucleus test and the in vitro chromosome aberration test: industrial experience," Mutation Research, vol. 392, pp. 45-59, 1997.

[29] Y. Sugimoto, Y. Iba, R. Kayasuga et al., "Inhibitory effects of propolis granular A. P. C on 4-(methylnitrosamino)-1(3-pyridyl)-1-butanone-induced lung tumorigenesis in $\mathrm{A} / \mathrm{J}$ mice," Cancer Letters, vol. 193, no. 2, pp. 155-159, 2003.

[30] D. Kirkland, "Chromosome aberration testing in genetic toxicology_-past, present and future," Mutation Research, vol. 404, no. 1-2, pp. 173-185, 1998.

[31] M. Hayashi, R. R. Tice, J. T. MacGregor et al., "In vivo rodent erythrocyte micronucleus assay," Mutation Research, vol. 312, no. 3, pp. 293-304, 1994.

[32] L. A. Abramsson-Zetterberg, J. Grawè, and G. Zetterberg, "The micronucleus test in rat erythrocytes from bone marrow, spleen and peripheral blood: the response to low doses of ionizing radiation, cyclophosphamide and vincristine determined by flow cytometry," Mutation Research, vol. 423, pp. 113-124, 1999.
[33] S. Itoh, M. Katoh, and K. Furuhama, "In vivo photochemical micronucleus induction due to certain quinolone antimicrobial agents in the skin of hairless mice," Mutation Research, vol. 520, no. 1-2, pp. 133-139, 2002.

[34] Vijayalaxmi, A. D. Kligerman, T. J. Prihoda, and S. E. Ullrich, "Micronucleus studies in the peripheral blood and bone marrow of mice treated with jet fuels, JP-8 and Jet-A," Mutation Research, vol. 608, no. 1, pp. 82-87, 2006. 


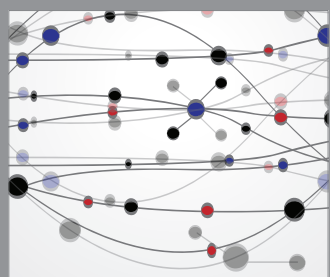

The Scientific World Journal
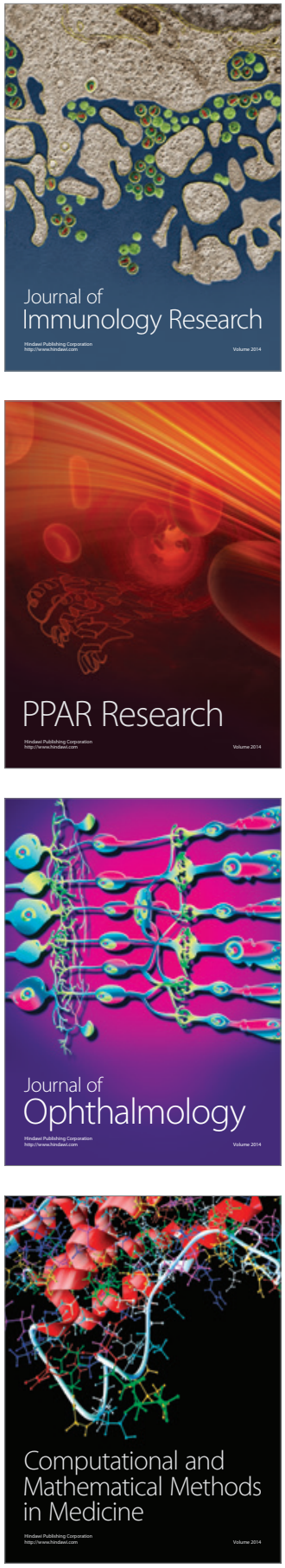

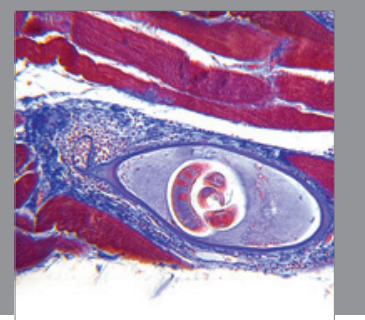

Gastroenterology

Research and Practice
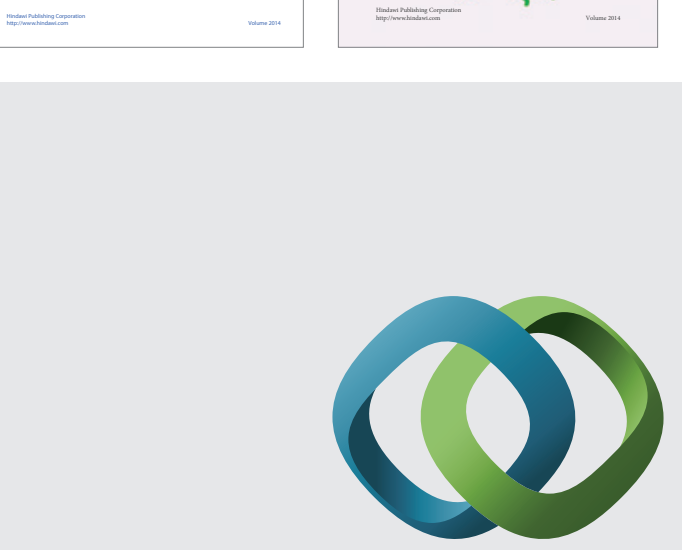

\section{Hindawi}

Submit your manuscripts at

http://www.hindawi.com
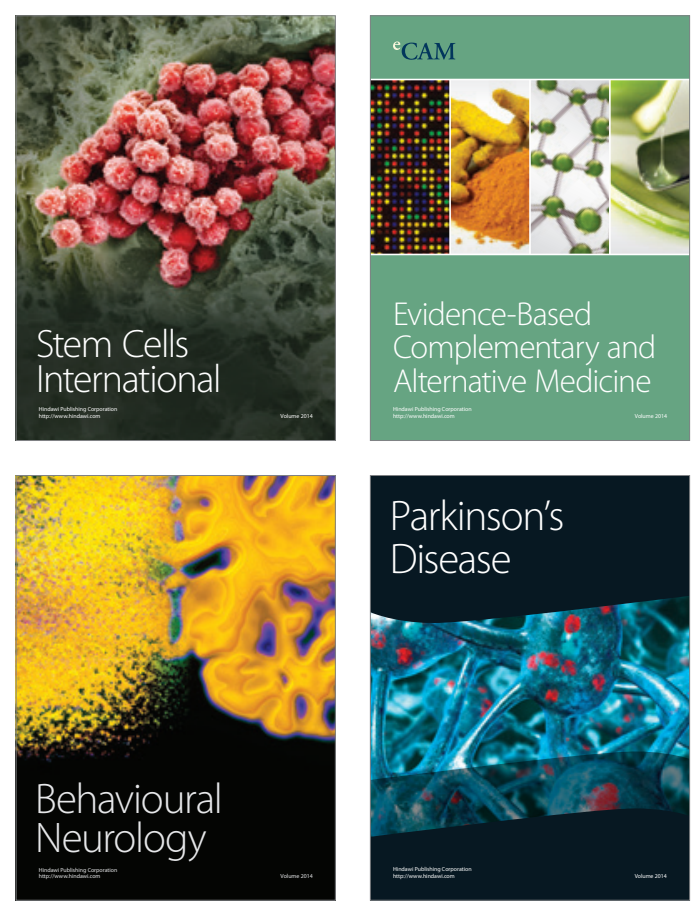

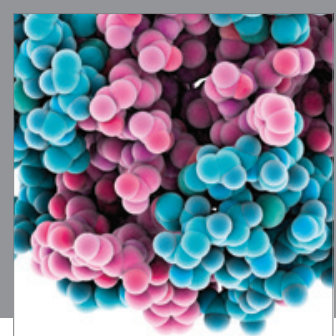

Journal of
Diabetes Research

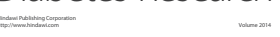

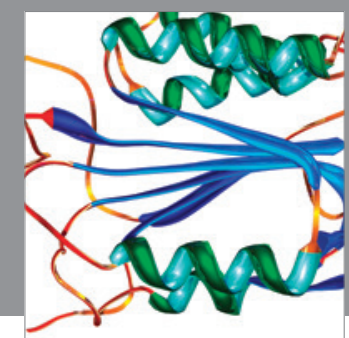

Disease Markers
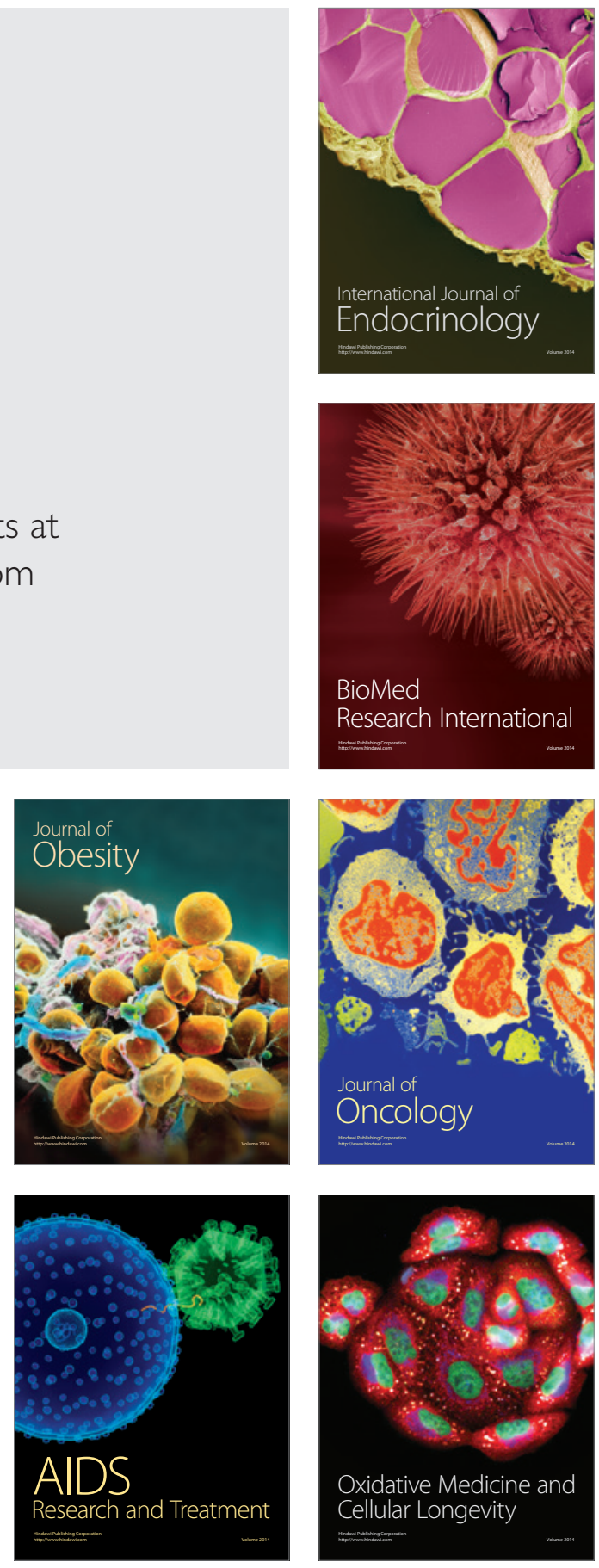